\title{
Efficacy and safety of anti-TNF agents in patients with enthesitis related arthritis
}

\author{
P Tynjälä*1, V Honkanen ${ }^{1}$, K Aalto ${ }^{1}$ and T Levälampi ${ }^{2}$
}

Address: ${ }^{1}$ Hospital for Children and Adolsecents, Helsinki, Finland and ${ }^{2}$ Rheumatism Foundation Hospital, Heinola, Finland

* Corresponding author

from 15th Paediatric Rheumatology European Society (PreS) Congress

London, UK. 14-17 September 2008

Published: 15 September 2008

Pediatric Rheumatology 2008, 6(SuppI I):P37 doi:I0.I I86/I546-0096-6-SI-P37

This abstract is available from: http://www.ped-rheum.com/content/6/SI/P37

(C) 2008 Tynjälä et al; licensee BioMed Central Ltd.

\section{Background}

Approximately $5-15 \%$ of patients with juvenile idiopathic arthritis belong to a subcategory of enthesitis related arthritis (ERA), which is strongly associated with HLA-B27 and male gender. Recent investigations have suggested markedly low discontinuation rates of antitumour necrosis factor (anti-TNF) agents in those with ERA, in whom reports on long-term efficacy and safety of anti-TNFs are still few.

\section{Patients and methods}

Based on Finnish register on biologic agents (ROB-FIN) in children, assessment of efficacy was available in 12 male patients with ERA, mean age being 13.6 years at anti-TNF onset (range 8.9-17.3), mean duration of ERA 2.6 years (range $0.2-6.3$ ), and mean follow-up on anti-TNFs 18.5 months (range 6.0-70). All patients were receiving their first course of anti-TNF agents; 7 infliximab, 4 etanercept, and 1 adalimumab.

\section{Results}

At 3 months, 100\% achieved ACR Pediatric 30\% improvement (ACR Pedi 30), 83\% ACR Pedi 50, 83\% ACR Pedi 70 , and $17 \%$ ACR Pedi 100 . At 6 months, these rates were $100 \%, 100 \%, 83 \%$, and $17 \%$; and at 12 months $100 \%$, 100\%, 83\%, and 17\%. Three patients achieved ARC Pedi 70 at 24 months, and one also at 60 and at 70 months. No-one discontinued anti-TNFs due to adverse events (AEs) or inefficacy. Two patients, one on etanercept and another on infliximab, discontinued the therapy due to clinical remission at 70 and 26 months, respectively. The former relapsed within 6 weeks. Per 100 patient-years, 7.7 AEs and 0.45 serious AEs occurred.

\section{Conclusion}

Anti-TNF agents seem to be safe and highly effective in ERA. 